\title{
Editorial
}

Nephrology

Published online: February 7, 2014

DOI: $10.1159 / 000358602$

\section{Is Dietary Acid a Modifiable Risk Factor for Nephropathy Progression?}

\author{
Nimrit Goraya ${ }^{a, b}$ Donald E. Wesson ${ }^{a, b}$ \\ ${ }^{a}$ Department of Internal Medicine, Texas A\&M College of Medicine, and ${ }^{\mathrm{b}}$ Department of Internal Medicine, \\ Scott and White Healthcare, Temple, Tex., USA
}

Treating metabolic acidosis in chronic kidney disease (CKD) as per current KDOQI guidelines appears to slow CKD progression $[1,2]$ and is an added reason to treat CKD-related metabolic acidosis when serum total $\left[\mathrm{HCO}_{3}\right]$ is $<22 \mathrm{mEq} / \mathrm{l}$ [3]. This recommendation is based on 'evidence and opinion' [3] but cautioned that 'more research is needed on the long-term effects of correcting acidemia on clinical outcomes...' [3]. Since these recommendations were issued, epidemiologic studies have shown that CKD patients with ranges of plasma $\left[\mathrm{HCO}_{3}\right]$ that include those $>22 \mathrm{mEq} / \mathrm{l}$ are associated with a greater risk for and a faster rate of glomerular filtration rate (GFR) decline [4-6]. In addition, $\mathrm{NaHCO}_{3}$ slowed the rate of estimated GFR (eGFR) decline in individuals with reduced eGFR but without metabolic acidosis [7]. Animal $[8,9]$ and human [10] studies support that reduced GFR is associated with acid retention, even with normal plasma $\left[\mathrm{HCO}_{3}\right]$. Furthermore, ameliorating this apparent acid retention in animals with reduced GFR but normal plasma $\left[\mathrm{HCO}_{3}\right]$ by adding dietary alkali or by eating diets that are base-producing rather than acid-producing slows GFR decline $[8,9]$. Proposed mediators of acid-induced nephropathy progression include compliment activation
[11], endothelin [10], and aldosterone [10]. Together, these studies suggest that patients with reduced GFR but no metabolic acidosis nevertheless have acid retention that might mediate nephropathy progression. Reducing acid retention with less acid-producing diets that lower net endogenous acid production (NEAP) might slow nephropathy progression in patients with reduced GFR even without metabolic acidosis.

Diets of those living in industrialized societies are largely acid-producing due to high intake of acid-producing animal protein and comparatively low intake of baseproducing proteins from fruits and vegetables [12]. These acid-producing diets increase NEAP [13] and typically do so without inducing frank metabolic acidosis in individuals with relatively preserved GFR, but might induce frank metabolic acidosis in those with very low GFR [14]. Diets higher in base-producing protein like fruits and vegetables reduce NEAP $[13,14]$ and reduce kidney injury in subjects with reduced eGFR without metabolic acidosis [15]. In support of the importance of NEAP in nephropathy progression, high NEAP was associated with faster GFR decline in individuals with reduced GFR [16], identical to the data of Kanda et al. [17] in this issue of Amer-

\section{KARGER}

E-Mail karger@karger.com

www.karger.com/ajn
(C) 2014 S. Karger AG, Basel

0250-8095/14/0392-0142\$39.50/0
Donald E. Wesson, MD

Texas A\&M College of Medicine

Scott and White Healthcare

2401 South 31st Street, Temple, TX 76508 (USA)

E-Mail dwesson@sw.org 
ican Journal of Nephrology in a different population. Because total dietary protein reduction did not slow GFR decline in a large prospective study [18], data to date support that the dietary protein effect on NEAP (i.e. whether acid- or base-producing) more importantly determines nephropathy progression than amount of dietary protein.

Kanda et al. [17] make at least two new and important contributions to this evolving story of the apparent benefit of lower NEAP on nephropathy progression in patients with reduced GFR. First, the benefit was shown in an exclusively elderly population (all were $\geq 60$ years of age with a mean age of 70 years), an age group that is at the highest risk for CKD and its progression [19]. These data support further studies to determine if prospectively reducing NEAP slows nephropathy progression in this comparatively high-risk group, one that has been comparatively understudied despite its high CKD prevalence and risk for progression to complete kidney failure [19]. Second, the benefit was shown in patients already on a low-protein diet (they were prescribed $0.6-0.8 \mathrm{~g} / \mathrm{kg}$ body weight/day and had measured intake of $0.8-0.9 \mathrm{~g} / \mathrm{kg}$ body weight/day). Despite achieving a level of total protein intake that was likely less than that ingested by CKD patients in most industrialized societies, the investigators showed detrimental effects of higher than lower NEAP on nephropathy progression within this range of NEAP that is likely lower than that for most CKD patients. The data additionally emphasize the greater importance of the character of ingested protein, i.e. whether acid- or baseinducing, rather than total protein on nephropathy progression. Unfortunately, Kanda et al. [17] did not report the types and amounts of dietary protein, but it seems safe to assume that those with higher NEAP ate a comparatively higher proportion of acid-producing compared to base-inducing protein.

The subjects reported by Kanda et al. [17] had CKD stages 3-5 eGFR with a mean eGFR of $23 \mathrm{ml} / \mathrm{min} / 1.73 \mathrm{~m}^{2}$, a level that is often associated with metabolic acidosis [20]. Nevertheless, mean serum $\left[\mathrm{HCO}_{3}\right]$ for their cohort was $>25 \mathrm{mEq} / \mathrm{l}$, consistent with the comparatively (i.e. compared to more typical patients in industrialized societies with similar eGFR) low dietary acid intake discussed earlier because patients with comparable eGFR in other settings would likely have frank metabolic acidosis $[14,20]$. Although some subjects were prescribed oral $\mathrm{NaHCO}_{3}$, its intake or level of serum $\left[\mathrm{HCO}_{3}\right]$ were not associated with nephropathy progression.

Although the study by Kanda et al. [17] makes important insights as discussed, its limitations support the need for follow-up studies to help address the important ques- tion as to whether reduced NEAP should be standard care for subjects with reduced eGFR. Their study was observational and retrospective rather than interventional and prospective. As mentioned, they also did not report important details like the character (animal or plant source, acid- or base-producing) of ingested protein. It would have also been helpful to have compared NEAP between patients who followed the recommended diet with those with less dietary compliance. Finally, we would like to have known serum the $\mathrm{pH}$ and $\mathrm{PCO}_{2}$ to better assess patient acid-base status. Despite these limitations, Kanda et al. [17] have helped identify important research directions that will lead to much-needed additions to available kidney protective therapies.

CKD is an increasing health burden, evidenced by an increase in CKD-related deaths and in years of life lost due to CKD between 1990 and 2010 [21]. This analysis supported diet as the single largest CKD-related death and disability risk factor [21], but further studies will better identify important dietary aspects that contribute to nephropathy progression. Analysis of contributing factors to CKD progression due to type 2 diabetes mellitus, the single largest CKD cause in the USA, showed that 'healthier' diets lower risk for nephropathy progression due to type 2 diabetes mellitus [22]. The analysis suggested that diets high in fruit, fruit juices, and leafy green vegetables reduce the risk for progression of CKD due to type 2 diabetes mellitus [22]. Because such diets reduce NEAP $[13,14]$, the data reported by Kanda et al. [17] are consistent with these two studies.

\section{Future Research Directions}

If larger-scale, prospective studies confirm that low NEAP slows nephropathy progression, additional questions need to be answered. Are reducing NEAP by adding alkali such as $\mathrm{NaHCO}_{3}$ or substituting base-producing for acid-producing dietary protein equally effective? When in the course of CKD should efforts to reduce NEAP begin? Should NEAP begin when GFR reduction is associated with metabolic acidosis, when GFR is reduced but before metabolic acidosis appears, or with signs of kidney injury, such as albuminuria, even when GFR and acid-base status are normal? Answers to these important questions will not only lead to better treatment strategies, but more importantly, to preventive strategies for CKD. 


\section{References}

$>1$ de Brito-Ashurst I, Varagunam M, Raferty MJ, et al: Bicarbonate supplementation slows progression of CKD and improves nutritional status. J Am Soc Nephrol 2009;20:2075-2084.

$>2$ Phisitkul S, Khanna A, Simoni J, et al: Amelioration of metabolic acidosis in subjects with low GFR reduces kidney endothelin production, reduces kidney injury, and better preserves GFR. Kidney Int 2010;77:617-623.

>3 National Kidney Foundation: K/DOQI Clinical Practice Guidelines for Nutrition in Chronic Renal Failure. Am J Kidney Dis 2000; 35:S1-S140.

4 Raphael K, Wei G, Baird B, et al: Higher plasma bicarbonate levels within the normal range are associated with better survival and renal outcomes in African Americans. Kidney Int 2011;79:356-362.

$>5$ Shah SN, Abramowitz M, Hostetter TH, et al: Plasma bicarbonate levels and the progression of kidney disease: a cohort study. Am J Kidney Dis 2009;54:270-277.

-6 Dobre M, Yang W, Chen J, et al: Association of plasma bicarbonate with risk of renal and cardiovascular outcomes in CKD: a report from the Chronic Renal Insufficiency Cohort (CRIC) study. Am J Kidney Dis 2013;62:670678.

7 Mahajan A, Simoni J, Sheather S, et al: Daily oral sodium bicarbonate preserves glomerular filtration rate by slowing its decline in early hypertensive nephropathy. Kidney Int 2010;78:303-309.
$>8$ Wesson DE, Simoni J: Increased tissue acid mediates progressive GFR decline in animals with reduced nephron mass. Kidney Int 2009; 75:929-935.

$>9$ Wesson DE, Simoni J: Acid retention during kidney failure induces endothelin and aldosterone production which lead to progressive GFR decline, a situation ameliorated by alkali diet. Kidney Int 2010;78:1128-1135.

10 Wesson DE, Simoni J, Broglio K, Sheather S: Acid retention accompanies reduced GFR in humans and increases plasma levels of endothelin and aldosterone. Am J Physiol Renal Physiol 2011;300:F830-F837.

11 Nath KA, Hostetter MK, Hostetter TH: Pathophysiology of chronic tubulo-interstitial disease in rats-Interactions of dietary acid loads, ammonia, and complement component C3. J Clin Invest 1985;76:667-675.

12 Remer T: Influence of nutrition on acid-base balance-metabolic aspects. Eur J Nutr 2001; 40:214-220.

13 Frassetto LA, Todd K, Morris Jr RC, Sebastian A: Estimation of net endogenous noncarbonic acid production in humans from diet potassium and protein contents. Am J Clin Nutr 1998;68:576-583.

14 Adeva MM, Souto G: Diet-induced metabolic acidosis. Clin Nutr 2011;30:416-421.

15 Goraya N, Simoni J, Jo CH, Wesson DE: Dietary acid reduction with fruits and vegetables or sodium bicarbonate reduces kidney injury in individuals with moderately reduced GFR due to hypertensive nephropathy. Kidney Int 2011;81:86-93.
16 Scialla JJ, Appel LJ, Astor B, et al: Net endogenous acid production is associated with faster decline in GFR in African Americans. Kidney Int 2012;82:106-112.

17 Kanda E, Ai M, Kuriyama R, et al: Dietary acid intake and kidney disease progression in the elderly. Am J Nephrol 2014;39:145-152.

18 Klahr S, Levey AS, Beck GJ, et al: The effects of dietary protein restriction and blood-pressure control on the progression of chronic renal disease. Modification of Diet in Renal Disease Study Group. N Engl J Med 1994;330: 877-884.

19 US Renal Data System: USRDS 2009 Annual Data Report. Bethesda, National Institutes of Health, National Institute of Diabetes and Digestive and Kidney Diseases, Bethesda, 2010.

20 Hsu CY, Chertow GM: Elevations of serum phosphorus and potassium due to mild to moderate chronic renal insufficiency. Nephrol Dial Transplant 2002;17:1419-1425.

-21 US Burden of Disease Collaborators: The state of US health: 1990-2010. Burden of diseases, injuries, and risk factors. JAMA 2013; 310:591-608.

22 Dunkler D, Dehgrhan M, Teo KK, et al: Diet and kidney disease in high-risk individuals with type 2 diabetes mellitus. JAMA Int Med 2013;173:1682-1692. 